NASA Technical Memorandum 108814

NASA-TM-108814 19940028421

Aviation Human Factors

Research in U.S. Universities:

Potential Contributions to

National Needs

R. Key Dismukes

March 1994
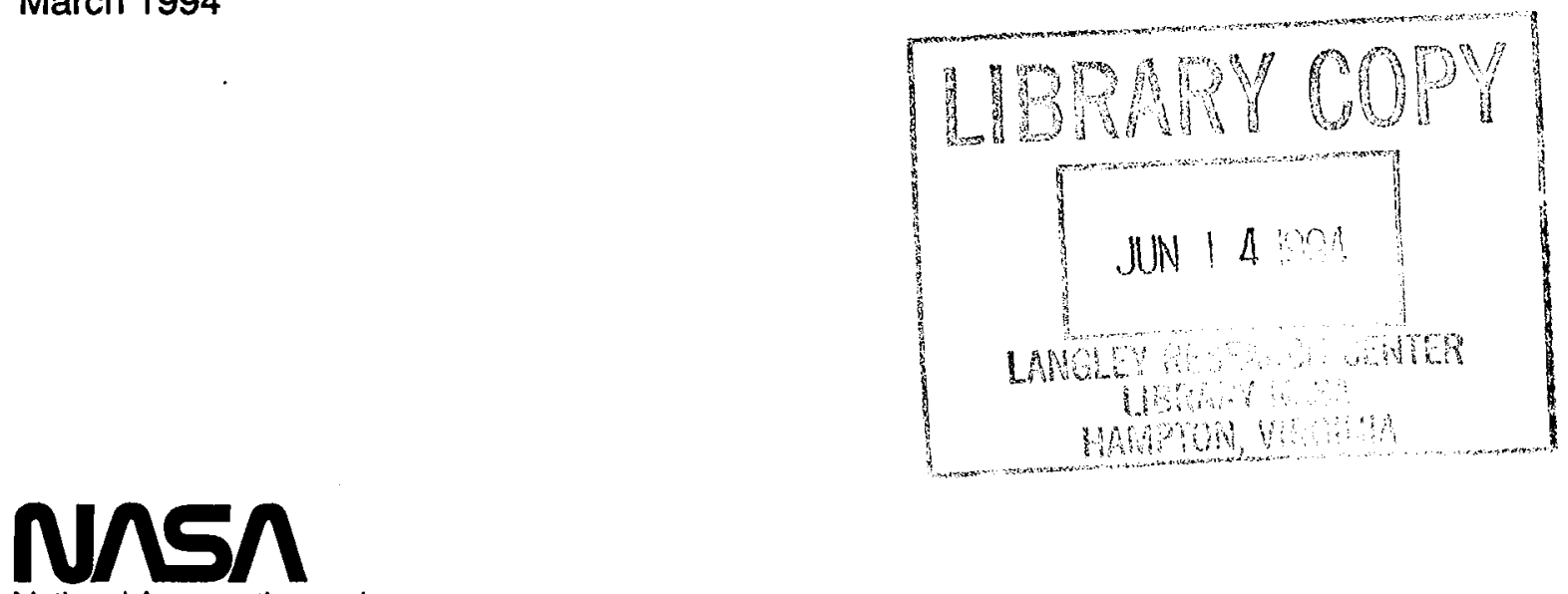

National Aeronautics and

Space Administration 

Aviation Human Factors Research in U.S. Universities: Potential Contributions to National Needs

R. Key Dismukes, Ames Research Center, Moffett Field, California

March 1994

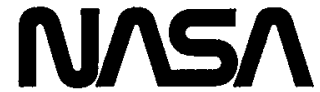

National Aeronautics and

Space Administration 



\section{Table of Contents}

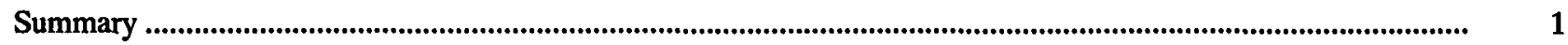

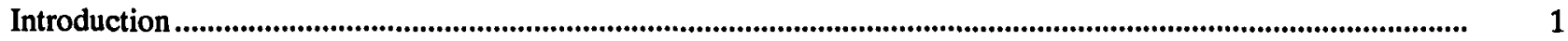

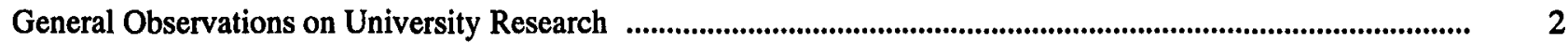

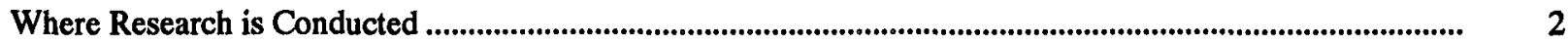

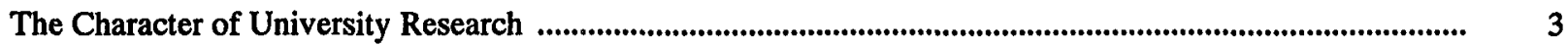

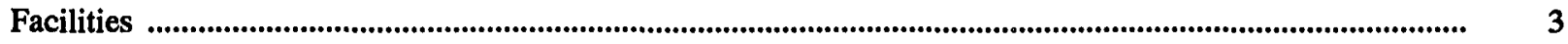

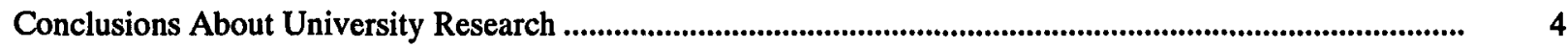

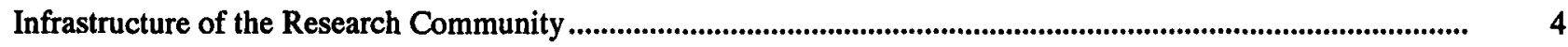

University Perspectives of the National Plan ...................................................................................................

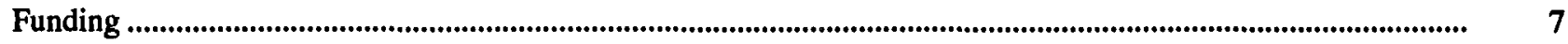

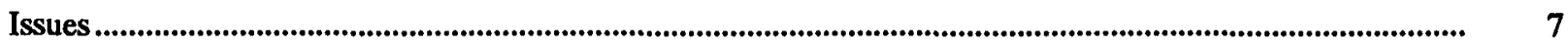

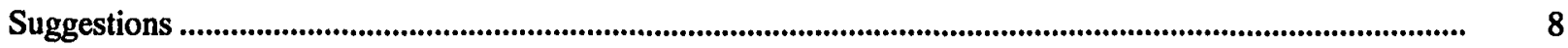

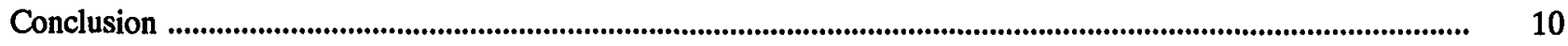

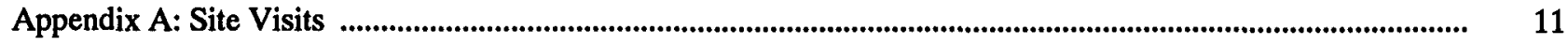

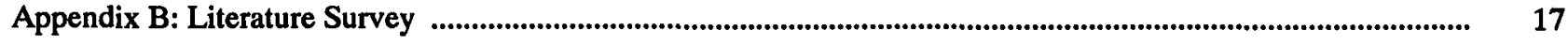

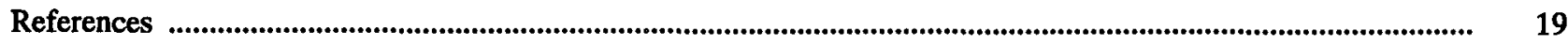




\title{
Aviation Human Factors Research in U.S. Universities: Potential Contributions to National Needs
}

\author{
R. KEY DISMUKES
}

Ames Research Center

\section{Summary}

Universities can and should make vital contributions to national needs in aviation human factors. However, to guide and utilize university research effectively we must understand what types of expertise and facilities universities can bring to bear on aviation problems. We should be aware of where relevant research is already underway and where untapped potential exists. How does the character of research in universities differ from and complement research in government and industry laboratories? What conditions would encourage universities to focus on national priorities and would promote high quality, relevant research? This paper attempts to address these issues. It is based on a survey conducted by the author, which included site visits to several universities, telephone interviews with faculty members at other universities, and a search of the aviation human factors research literature.

\section{Introduction}

Human factors research is increasingly recognized as vital to the safety and efficiency of aviation operations (refs. 1-4). Recognizing this, the Federal Aviation Administration (FAA), in consultation with other gov ernment agencies, industry, and human factors experts, developed a National Plan for Aviation Human Factors (ref. 5). This plan identifies operational issues in which human performance is crucial and calls for a program of research to address those issues.

Universities can and should make vital contributions to national needs in aviation human factors. However, to guide and utilize university research effectively we must understand what kinds of expertise and facilities universi ties can bring to bear on aviation problems. We should be aware of where relevant research is already under way and where untapped potential exists. How does the character of research in universities differ from and complement research in government and industry laboratories? What conditions would encourage universities to focus on national priorities and would promote high-quality, relevant research? This paper attempts to address these issues.

Universities are the foundation of the U.S. research and development enterprise. Fundamental research in this country is conducted predominantly, though not exclusively, in universities. The success of this arrangement is attested to by the eminence of U.S. scientists in scientific disciplines that have dramatically advanced our understanding of the world in which we live and have fostered revolutions in the way we live. For example, basic biomedical research has generated a wide range of medical breakthroughs, and basic research in solid-state physics enabled the computer revolution that now shapes almost all aspects of industry.

Applied research, in contrast to basic research, is distributed more evenly among universities, industry, and government laboratories, and some aspects of applied research are probably best done outside universities. However, for several reasons, universities do have a special role in applied research that distinguishes them from government and industry efforts.

1. On the campus of a good university one finds a wide range of frontier research in both basic and applied sciences. This provides a pool of knowledge, experimental techniques, and methods of analysis that can be focused on specific applied problems. And the interactions among scientific disciplines at universities can provide a major source of innovation.

2. Involving university scientists in research on aviation issues spreads awareness of those issues among the scientific community. University scientists discuss their research extensively with members of their own research teams, with other members of the faculty, and with the broader scientific community. As other scientists become aware of aviation issues they begin to think of ways in which their particular methods and knowledge could help resolve those issues. This leverages the funding other agencies have invested in these research domains.

3. University research on aviation human factors will expose graduate and undergraduate students to this domain. This will provide a new generation of scientists 
well prepared to work on aviation issues. It will also increase the probability that the next generation of engineers and managers grasp the importance of human factors.

4. University research plays a central role in setting qual ity control standards for the entire scientific community.

Last winter I conducted a survey of universities in order to expand my understanding of the research they are currently conducting in aviation human factors and their potential for expanded contributions to this domain. The survey included visits to six universities (appendix A), telephone interviews with faculty members at several other universities, and a literature search (appendix B). My choice of places to visit was arbitrary; however, I attempted to obtain a good sample of the various kinds of organizational arrangement, the kinds of facilities available, and the range of research under way in U.S. universities. Although this sample was by no means comprehensive, it seems fairly representative. I also drew upon visits I have made to various universities for other purposes over the past several years.

In making this survey, I have drawn liberally upon comments and suggestions offered by many university scientists; however, the opinions expressed in this report are strictly my own.

\section{General Observations on University Research}

A substantial amount of research on aviation human factors is already under way in U.S. universities and there is a large potential for expanding those research efforts to help address the many issues framed by the National Plan. The universities are a large reservoir of talent, knowledge, and techniques that can be brought to bear on aviation problems.

\section{Where Research is Conducted}

More than 50 U.S. universities conduct research in aviation human factors (appendix B). The size and organizational settings of these research programs vary greatly. Several hundred colleges and universities have aviation departments that offer undergraduate degrees in aviation, but not many of these departments conduct research.

Most university research on aviation human factors is done in either psychology or engineering departments. Although only a few universities have large programs in aviation human factors, several universities have insti tutes or centers, with ties to other academic departments, with the specific mission of fostering aviation human factors research. With the exception of these few schools, collaboration across academic departments is rarely substantial, even though aviation human factors is inherently a trans-disciplinary domain.

Only a few schools have more than a handful of faculty members working in this area; consequently, half or more of the total literature comes from schools with no more than three faculty members concerned with aviation human factors. In fact, some of the best known research on particular topics is conducted in universities in which only one senior faculty member works on aviation human factors. Also, many faculty scientists working on human factors issues address aviation as only one of the various applications of their work. Thus it is difficult to produce a complete profile of the research being conducted in this field.

Do schools with large programs do better research than those with only a few faculty members working on avia tion human factors? In most respects, I conclude that the answer is no. Primarily, the larger programs simply cover a wider range of research topics. However, they probably do have some advantage in having a larger pool of knowledge about aviation issues which the faculty and students can share with each other. But within a particular specialty topic, the quality and relevance of a single faculty member's research group are often as good as the work from large university programs. The large university programs do have a special role in training students who want a broad exposure to aviation human factors.

Perhaps most relevant is whether a school in assessing these programs sets high standards for research quality. The various schools in which aviation human factors research is conducted vary dramatically in their overall reputation as research institutions. However, this measure cannot be simply applied, because U.S. universities are ranked primarily on the eminence of their basic research departments and, to some extent, on the caliber of their engineering schools. Most U.S. psychology departments, particularly in prestigious universities, do not regard applied research (sometimes with the exception of industrial and clinical psychology) nearly as highly as basic research, and do not attempt to recruit strong faculty capabilities for applied topics such as aviation human factors. Applied work is, by definition, accepted in engineering departments, but in many cases engineering departments regard research on human performance as too "soft" or too far from the center of gravity of the department's expertise.

For these reasons, those few universities with broad reputations for excellence who actively support aviation human factors-though they have no monopoly on highquality work-do have a special role in establishing this 
emerging field as an appropriate domain for U.S. universities. Also, those few schools with true collaboration across academic departments can do much to strengthen the trans-disciplinary character of aviation human factors.

\section{The Character of University Research}

More than any other type of research organization, universities are able to tap developments across a broad range of science and technology to develop more powerful approaches to the resolution of aviation human factors issues than those that currently exist. For example, a deep understanding of human cognitive processes is required to answer many of the practical issues raised by automation of the flight deck, issues such as how to keep the crew in the loop, how to aid decision-making, and how to minimize human error.

The emergence of cognitive science over the past three decades has revolutionized behavioral science and provided new insight into how humans obtain, organize, process, store, and retrieve information. For instance, traditional normative theories of optimal decision-making have been thrown on their ear by recent studies demonstrating that in reality human experts use far different heuristic processes to assess situations and reach decisions. Another implication of modern cognitive science is that human error among highly skilled, strongly motivated individuals such as aircrew members is only rarely explained by carelessness and more commonly is a product of systems and procedures mismatched to the mechanisms of human information processing.

Cognitive science is being funded by basic research agencies such as the National Science Foundation (NSF) and by mission agencies such as the National Institute of Health (NIH), which have encouraged application to areas such as medical decision-making. With appropriate funding, universities could play a leading role in bringing this new discipline (and others) to bear on the operational problems of aviation.

One might ask if university scientists have sufficient access to the real world of aviation operations to conduct realistic research and if they are sufficiently motivated to do this kind of work. From my site visits I conclude that the answer to both questions is a qualified yes. A number of university scientists have established close working relationships with airlines, for example. In fact, the best known field studies on aircrew attitudes toward automa tion and on crew coordination issues have been done by university scientists. Some university scientists are developing relationships with industry flight deck designers, few have become broadly familiar with operational issues, and others have focused effectively on one or two particular issues.

Several universities have large pilot training programs that provide an opportunity for certain types of aviation human factors research. Both student pilots and instructors are available as research subjects. The students provide an opportunity to study various aspects of and approaches to $\mathrm{ab}$ initio training, and the instructors can be used in perceptual and cognitive studies that require pilot subjects but that do not require the subjects to be experienced in large aircraft operations.

University scientists have demonstrated that they can work on real-world aviation issues and deliver products relevant and useful to the industry. Nevertheless, the interaction with industry is a potential choke point. Learning the details of operational procedures and systems takes considerable time, and much of the information cannot be obtained by the traditional academic method of reviewing published literature. The operational community has provided opportunities (e.g., attending simulator transition training) for a few scientists, but it cannot provide this exposure for a large population of researchers. Junior faculty members often have trouble getting their universities to permit them to spend the required extended periods away from the university for this kind of work.

Fortunately, it is not always necessary for scientists to become in-depth experts on flight operations or to personally develop a formal relationship with industry. Government laboratories can act as a bridge between industry and the universities, providing contacts and information about problems, priorities, and operational details. This bridge functions best when the government laboratory conducts research in collaboration with a university rather than simply farming the work out on contract. Also important are exchange programs that let university scientists spend substantial time in government and industry laboratories and, conversely, allow government and industry scientists to spend time at the universities.

Some university scientists are already involved in such collaborations or exchanges, but these arrangements tend to be catch-as-catch-can. Systematic, extensive involve ment of universities in the National Plan would be greatly aided by funding and advertising formal programs of this sort.

\section{Facilities}

For the most part, universities seem to have adequate facilities for research in aviation human factors. Much of the laboratory research in this field is done with 
workstations, some with high-resolution graphics systems, and the universities I visited seem to be as well or better equipped than government laboratories in these respects. A few universities with large aviation research programs have flight simulators instrumented for research, usually small-aircraft simulators with limited flight deck automation. These simulators are useful for some aviation research questions but not for others (e.g., they would not be useful for studying automation issues in air transport operations).

Many research issues concerning flight deck or air traffic control (ATC) automation can be studied in part-task simulations run on workstations available at universities. However a small subset of questions can be studied effectively only in realistic, large-aircraft full-system simulation. Few such facilities are dedicated to research and they are found only in government laboratories. (On occasion, airlines and aircraft manufacturers have allowed their training simulators to be used for research.) Government laboratories might enhance the payoff from the use of these rare and expensive research facilities by more systematically drawing university scientists into the design and conduct of simulation research.

\section{Conclusions About University Research}

Universities are a primary source of in-depth technical expertise. The character of university research complements that of research in government and industry laboratories. University scientists are in an excellent position to tap advances in basic sciences and apply them to the issues of aviation operations, and universities are an important source of new and powerful research methods. The university tradition of reductionism, rigorous methods, and critical debate of interpretations of results is a valuable counterbalance for government and industry laboratories, which are often under pressure to get results fast and provide unequivocal recommendations for avia tion operations. Furthermore, the research projects of uni versity scientists' provide a spin-off benefit by training graduate students to do research, thus promoting the next generation of scientists and practitioners in aviation human factors.

On the other hand, university scientists have usually not led the way in addressing the complex, ill-defined issues of human performance in the real world, whereas the government and industry laboratories are forced by their missions to grapple with these difficult issues. Many government and industry scientists have considerable expertise in aviation systems and operations, and their laboratories have unique simulation facilities and access to aviation operations for field studies. Understanding complex human performance in the real world requires integration of well-controlled laboratory studies, low- and high-fidelity simulation research, and field studies of actual operations. This integration can best be achieved by close collaboration among university, government, and industry scientists.

\section{Infrastructure of the Research Community}

The role of university research in aviation human factors has to be understood in the context of work done by other research organizations and the infrastructure of the field as a whole. The ability of a research community (e.g., those scientists working in a research specialty area) to address the problems of its particular domain in a powerful way hinges on the infrastructure of that community. By "infrastructure," I mean that the community shares, to some degree, the following.

1. A common perception of what the research domain is. What are the topics and phenomena of interest? What are the crucial questions to be addressed to advance the field? A common awareness and shared literature of previous research in the domain underlie current research activities of the community.

2. A set of methods and theories, with some degree of consensus on which methods and theories have power and validity for addressing specific issues.

3. Mechanisms for exchanging and discussing experimental results and theories and for debating and eventually resolving competing explanations. These mechanisms-which include publication, peer review processes, open meetings, and personnel exchangessupport the continuous process of duplication (or failure to duplicate), extension of original findings, and incorporation of results into the larger body of scientific knowledge. (Many nonscientists erroneously assume that the process of science consists of individual scientists making discoveries, publishing, and then moving on to the next question. In fact, however, publication of a result is only the first step of a reverberating process in which the research community discusses, analyzes, duplicates [or fails to duplicate], extends, interprets, and eventually incorporates a finding. Historians and philosophers of science point out that this social process of reaching consensus is intrinsic to the nature of science.)

4. Training programs to produce scientists qualified in the particular domain.

The infrastructure of aviation human factors, as a rela tively new field of research, is still emerging. I suggest several aspects of this infrastructure in its current state are worth noting. 
1. The research techniques of aviation human factors draw upon many scientific disciplines and are far more diverse than the techniques of most research specialties. For example, among the techniques employed at NASA Ames Research Center are field observations, survey questionnaires, full-mission simulation, physiological recording, linguistic and communication analyses, cognitive modeling, perceptual psychophysics, and computerbased design. Many of these techniques, taken from the parent discipline of human factors or other disciplines, are well established. Other techniques are still emerging. Thus a scientist in this field attempting to understand the work of his or her colleagues faces a formidable task. In some subspecialties of this field only one or two scientists are conducting research (in contrast to larger fields, in which many scientists work in each subspecialty). Some research techniques (e.g., full-mission simulation) are not available to most scientists. For these reasons, the crucial process of duplication, reinterpretation, and extension of results - central to progress in science-is more difficult in aviation human factors. Some of the most important kinds of studies in this field require multiple techniques, cutting across several disciplines. This raises questions about how to assemble research teams that collectively have the required expertise.

2. The study of human performance in real-world situations is the most complex topic in all of science. Much work is still required in the fundamental disciplines of psychology, sociology, and neuroscience to develop powerful, relevant models of human behavior that can be applied in aviation human factors work. Many important operational problems cannot be answered decisively because we do not yet have sufficiently penetrating research methods for elucidating human behavior. Because the study of human behavior is still in a rudimentary state, we lack the rich interaction among basic research, applied science, and technology that is characteristic of fields such as solid-state physics.

On the other hand, this field is ripe with opportunity, in part because cognitive science has emerged in recent times as a powerful new approach to understanding the mechanisms that underlie the skilled performance of experts such as pilots and controllers. Cognitive scientists are motivated to study such experts because when these experts are operating in the domain of their particular expertise they use cognitive procedures quite differently than do inexperienced subjects. Aviation human factors offers a particular advantage for this kind of study because expertise is crucial for human operators in aviation, consensus exists among domain experts (e.g., pilots) about what qualifies as expertise, and the work of the expert is fairly well described and well bounded (in contrast to that of artists, for example).
3. Access to the phenomena of interest is more difficult in this field than in many areas of science. Scientists must become deeply familiar with aviation operations to design effective, relevant research. For some types of study they must have access to expert subjects and for other types of study they must have direct access to actual flight or ATC operations. Realistic simulation facilities are very expensive and out of the reach of most university scientists. (Of course, much research can be conducted with part-task simulation and with traditional laboratory techniques.)

4. Not infrequently, the aviation operational community picks up research findings as soon as they are announced and applies them in setting policy, to procedures, and to the design of equipment. This is problematic for several reasons. It by-passes the process of discussion, duplication, and integration that the scientific community considers crucial in validating and interpreting findings.

Decision-makers in the operational world generally lack the technical expertise to understand the limitations of a particular finding and may unwittingly generalize the finding inappropriately. Scientists may or may not be conscientious about warning decision-makers that com peting explanations of the data have not yet been ruled out, but these caveats, even when articulated, are not always heard. Similar problems sometimes occur in other fields of science, especially those that are evolving rapidly and have great social import (e.g., molecular biology and artificial intelligence), but the problem seems more common in aviation human factors.

Decision-makers often cannot wait for the scientific community to complete the arduous process of reaching consensus. We need institutional mechanisms to provide decision-makers with the best available scientific judgment, along with appropriate cautions about the limits of certainty, in language nonscientists can understand.

5. Articles in scientific journals constitute only about a third of the technical literature on aviation human factors (appendix B). Most of the other literature is distributed roughly evenly among symposia proceedings, government technical reports, and contractor reports. This distribution is in contrast to that in basic research disciplines and to many areas of applied science in which the great majority of research is published in peer-reviewed scientific journals. The pattern of publication in aviation human factors appears to more resemble that of applied engineering.

This pattern is problematic for the purposes of a research community. Although scientists can in principle obtain government technical and contractor reports, these reports often are not disseminated widely. Many symposia proceedings are not picked up by the libraries that many scientists use as their primary access to the technical 
literature. The work that is published in scientific journals is spread among many journals, some of which only occasionally carry an article on a particular specialty topic bearing on aviation human factors. Thus, dissemination of the research literature in this field and ready access to that information appear to be less than desirable.

The FAA is considering establishing a relational database of research conducted under the auspices of the National Plan, an idea that could have a major beneficial effect on the field. I suggest that it would be crucial to include in this database all work published in aviation human factors, not just that sponsored by federal agencies under the plan. Furthermore, to have significant effect, this database must be adequately funded and staffed and carefully designed to meet customer needs. It must be easily accessible to a broad range of scientists and other users, and charges to users should be kept low to encourage its use. Scientists, in particular, need a way to quickly scan on a regular basis for new additions to the database in their areas of interest. This need might be met by something similar to Current Contents (a weekly listing of the tables of contents of scientific journals), a mechanism widely used in the basic research community.

Another, even more serious problem, is that research not published in peer-reviewed scientific journals is removed from a process central to the operation of science: detailed discussion among the scientific community of the experimental design, data, and conclusions of research studies. This process is the primary mechanism for quality control in science and the route through which individual studies become incorporated into the body of scientific knowledge.

6. This research community has not yet organized the kind of systematic lobbying presence that other research communities have found quite effective in promoting their fields. By "lobbying," I mean: communicating clearly and with political astuteness to Congress and federal agencies how aviation human factors can address important public problems and agency priorities; helping agencies identify the most crucial research questions and the most powerful research methods for addressing operational needs; and helping agencies evaluate research proposals and programs. (However, because many scientists in this field are employed by federal agencies or industry, they do help shape their organizations' programs through their individual positions.)

This lack of an organized lobbying presence may be one reason that aviation human factors is funded by federal agencies at levels far lower than that of some other disciplines that are no more relevant to the public welfare. In many areas of basic and applied science, universities have worked together to systematically portray to Congress, federal agencies, and the public the social benefits to be derived from funding these areas of science. These lobby ing efforts have been aided by close collaboration with the beneficiaries of the research. For example, public interest organizations comprising patients and families of patients with certain diseases have persuaded Congress to allocate large sums for research aimed at the prevention and treatment of diseases of interest.

It appears that the aviation human factors research community might advance its cause by emulating the efforts of other research communities, emphasizing how this research can contribute to public safety and to the efficiency of aviation operations.

7. The infrastructure of aviation human factors has much in common with that of the general field of human factors. In fact, no sharp boundary exists to distinguish aviation human factor, and many important contributions to this field come from studies that do not specifically involve aviation systems or operations. (Arguably, avia tion human factors is a subset of the larger field of human factors; still, the research questions and methods of aviation human factors are at least as diverse as those of the larger field.) Both the aviation human factors community and the overall human factors community consist of a mixture of researchers and practitioners whose interests overlap only partially. For example, some practitioners within the Human Factors Society complain that the research reported in the Human Factors Journal is too esoteric to help with problems they face in practice. Consequently, the Society is launching a new journal, Ergonomics in Design, that will emphasize practical problems.

8. Several organizations promote interaction among scientists and practitioners within the field of aviation human factors. The Association of Aviation Psychologists and the Aerospace Systems Technical Group of the Human Factors Society each have several hundred members (with considerable overlap among membership) and each publishes an informal quarterly newsletter. Recently the Aerospace Medical Association has formed an Aerospace Human Factors Committee and an Aerospace Human Factors Association.

Ohio State University, the Association of Aviation Psychologists, and the International Journal of Aviation Psychology co-sponsor a biannual symposium on aviation psychology. The Inter-national Journal of Aviation Psychology, published quarterly, is the only journal devoted to this field. Reports of aviation human factors research appear in a diverse set of other journals (see appendix B). 
In summary, when I compare aviation human factors with other, longer-established scientific disciplines, I have less sense of community, in spite of the good work of the organizations mentioned above. I find less consensus on methods, on critical questions, and on who the leading scientists are to serve as role models. Perhaps this is because aviation human factors is inherently a heteroge neous field.

I believe that strengthening the infrastructure of aviation human factors would have many benefits: it would enhance the quality of research, facilitate the transfer of research results to aviation operations, attract students to the field, and encourage new sources of funding. Perhaps it would be useful for representatives from the various organizations concerned with aviation human factors to meet for the purpose of developing an agenda for promot ing this field.

\section{University Perspectives of the National Plan}

During my site visits I attempted to determine the perspectives from which university scientists view the National Plan for Aviation Human Factors. Although diverse comments were made, several themes were pervasive.

In general, the university community seemed to view publication of the plan as useful to their interests. The plan provides them a much needed statement of current aviation operational problems and a list of corresponding research objectives from the FAA and NASA. University scientists have clear ideas about how they could con tribute to those research objectives, but they expressed confusion over how the FAA and NASA intend to involve universities in implementing the plan. The universities are particularly concerned that federal agencies be explicit about how the universities can do business with them.

Among the specific questions that were raised were the following: What is the probability that a research proposal, if it is scientifically strong and relevant to specific objectives of the plan, will be funded? Will these agencies reveal how much money and how many grants they will provide each year in various domains of the plan? Will there be true open competitions that will be widely announced and will adequate time be allowed so that well-thought out proposals can be prepared? Will the selection process be explicitly described in sufficient detail so that scientists preparing proposals will not have to play a guessing game? What mechanisms will be used to provide thorough technical evaluation of the scientific merit of proposals and what mechanisms will be used to determine operational relevance? Do the federal agencies recognize that many of the objectives of the plan require medium- to long-range research efforts?

Many university scientists recognize that integration of their work will require collaboration with government and industry laboratories and with the operational community. Several asked what mechanisms are envisioned to facili tate this collaboration.

The answers to these questions will largely shape the extent to which the best of the university community seriously attempts to participate in the plan.

\section{Funding}

\section{Issues}

The attainment of the ambitious goals of the National Plan will require a substantial increase in funding. If funding is made available, universities could expand their research in aviation human factors and become a partner with government and industry in this endeavor.

However, effective utilization of the university community depends as much on the design and management of research funding programs as it does on the level of funding. The character of the domains of science is very much shaped by the way support is provided by funding agencies. For example, the dramatic success of biomedi cal research in this country could not have been achieved if the NIH (the primary source of grants for biomedical research) had not set broad, long-term goals with stable objectives; provided funding at levels appropriate to the goals; awarded grants through open competition; and selected winners on the basis of well-defined criteria for scientific merit.

Lewis Thomas illustrates this point by pointing out that the NIH, charged with addressing the polio epidemic in the 1950 s, might have responded by using the bulk of its funds to improve treatment of polio victims - better iron lungs. Instead, the NIH invested heavily in discovering the root causes of polio. Now we no longer need iron lungs because polio has been eradicated in this country. This illustrates that long-range research can be focused on customer (in this case, public) concerns.

Funding for aviation human factors research, to date, has taken a very different form. Most of this funding comes from the Department of Defense (DOD), NASA, or the FAA, and most of it comes in the form of contracts or grants to address very specific, immediate problems. This is appropriate as far as it goes, but the net result is a field of research that is rather fragmented. Much of the knowledge generated within these constraints is not additive; 
often it does not generalize beyond the specific piece of equipment or operational setting to which the research was addressed.

Several of the senior university scientists I interviewed expressed concern that aviation human factors research has spent much effort on the nuts and bolts of particular operational problems and relatively little effort on getting at the underlying causes of those problems. This is in part because it is difficult to get funding for more generic approaches that would be at first be slower but ultimately could provide more far-reaching solutions.

By "generic" I mean research whose results are not limited to a particular piece of equipment, design format, or operational procedure. Generic applied research addresses broad categories of questions underlying an operational domain (e.g., decision-making in the cockpit). Generic applied research is distinct from fundamental research, whose results ultimately contribute to many domains in ways that are almost impossible to predict. Fundamental research, in contrast to generic applied research, is fairly well-funded in the United States. Several European countries place more emphasis on generic applied research than does the United States.

Lack of funding is not the only problem. Various obstacles limit the influence of human factors research in general on the design and operation of aviation systems. These obstacles are beyond the scope of this article, but one can find a continuing discussion of them in issues of the Human Factors Bulletin.

University scientists also expressed concern that, unless one already has a relationship with a DOD, NASA, or FAA manager who has funds available, it is difficult to know how to approach these agencies with proposals for research in aviation human factors. This is in contrast to agencies that have grant programs with well-defined procedures (e.g., NIH, NSF, and the basic research offices of the three military services). NASA has used grants in this field for several years, and the FAA has recently been given authority to use Broad Area Announcements (a government procurement mechanism) to let grants. However, neither agency operates a systematic, widely advertised, open competition for investigator-initiated proposals covering the full range of the National Plan.

Good scientists have opportunities to get grants from various agencies and are less likely to seek funding for research on aviation human factors if the probability of obtaining funding for a well thought out proposal is unrealistically low. University scientists need assurance that contract awards are based on expert evaluation of scien tific merit, achievability, and true relevance to operational problems. Without this assurance, government agencies may find that many of the scientists induced to submit proposals for aviation human factors are those who would have trouble getting funds elsewhere. And less-thanexcellent scientists are unlikely to make a dent in the complex problems of human performance in aviation.

Another concern was the lack of stability in funding. Consulting firms are much better able than universities to pick up a new topic, hire people, and grind out a result in a year or two. But university science, by nature more penetrating, has longer time constants. It takes several years to establish a laboratory that can turn out good work in a given area. In an effective laboratory the series of topics studied are closely related so that the methods and results of one study can be applied to the next. A laboratory whose efforts are directed from one to another of a widely divergent range of topics is rarely effective.

\section{Suggestions}

The FAA and NASA could effectively engage the best of the university research community in the goals of the National Plan by drawing upon the lessons learned by other mission agencies in the grant programs they have operated for several decades. I suggest below what I think are the most salient implications of those lessons.

Soliciting research proposals-Grant-opportunity announcements should be published widely in media that scientists read (they do not read Commerce Business Daily!). Scientists must be given adequate time to prepare quality proposals. Most granting agencies have found 6 months to be absolutely minimal for adequate response. One-time opportunities are generally far less effective than continuing programs that advertise annually and let at least a few new competing grants each year.

To help scientists focus proposals appropriately and to reduce the number of spurious proposals, an announcement should contain information about the maximum size and duration (nominally 3 years) of the award, the kinds of research that will be considered, the way the proposals will be evaluated, the date when a decision will be announced, and the number of awards that will likely be made.

Evaluating research proposals- Proposals should be evaluated rigorously for both scientific merit and relevance to the National Plan. In applied research (as opposed to basic research) scientific merit basically means the extent to which the experimental design is capable of answering the question that it proposes to address. Some subordinate questions: Are the starting assumptions valid? Is the method appropriate and powerful? Can the approach distinguish unequivocally which of competing explanations is correct? Will the conclusions 


\section{Appendix A}

\section{Site Visits}

In choosing universities to visit I attempted to sample the various types of organizational arrangements, the kinds of facilities available, and the range of research under way. This sample is by no means comprehensive, but I think it is fairly representative. I have not attempted a critical evaluation of the merit of the research conducted at these universities. Such an evaluation would take visits longer than the one or two days I spent at each university and would require a detailed review of the published work of all the faculty members. Instead, in the pages that follow, I attempt to illustrate by example the kinds of contribu tions that universities can make to aviation human factors. In my discussions, I also asked university scientists for their observations on the infrastructure of this field and solicited their ideas on what would promote their contributions to the goals of the National Plan.

\section{Center for Applied Human Factors in Avlation}

The new Center for Applied Human Factors in Aviation (CAHFA) is a collaboration between the University of Central Florida (UCF) in Orlando and Embry-Riddle Aeronautical University (ERAU) in Daytona Beach. Unlike many university "centers," which are little more than rubrics designed to package diverse research programs to attract funding, CAHFA appears to be a genuine and active collaboration. The expertise of the two faculties is complementary and interaction between faculty members is evident.

The UCF side of CAHFA is based in the psychology department. This medium-sized department offers a doctorate program in human factors and graduate students can specialize in aviation problems. A partial list of the research interests of the CAHFA core faculty on the UCF side includes crew coordination, team training and team decision-making, effects of stress on teams, visual performance, qualities of visual displays, lighting and signage in transportation, flight displays, flight training and safety, human-computer interaction, synthetic speech, knowledge representation, problem-solving, testing for job selection, and organizational psychology.

Faculty members in other departments can be drawn into CAHFA collaborations. For example, the computer engineering department is developing an expert systems shell for use in an intelligent ATC training system developed at
ERAU. The Institute for Simulation and Training, an offcampus research institute, is also available for collaboration.

ERAU provides undergraduate training in aeronautical science, aviation business administration, aircraft mainte nance, maintenance management, aviation computer science, avionics technology, and several related areas of engineering. Master's degree programs are available in some of these areas. Among the specialized facilities supporting these training programs as well as research is a fleet of light aircraft and flight simulators, an airway sci ence laboratory that simulates the elements of the National Airspace System, and a maintenance technology center with reciprocating and turbine laboratories.

Fairly recently, ERAU has begun expanding its research programs in areas relevant to aviation human factors. A partial list of the faculty research interests includes psy chological test batteries for selecting ATC personnel, use of simulators and intelligent systems for training ATC personnel, management of four-dimensional traffic flow in the ATC system, methods and devices for improving student pilot instruction, evaluation of PC-based flight training devices, accident risk analysis, and human factors issues in airway systems management.

CAHFA faculty can conduct research on a variety of topics relevant to the National Plan. However, I believe that CAHFA's greatest strength-one that distinguishes it from most other organizations-lies in research on training issues. The ERAU faculty has broad practical experience in training entry-level pilots, controllers, mechanics, avionics technicians, and engineers. Moreover, the stu dents constitute a valuable pool of subjects. UCF and ERAU faculty are in a good position to use the technologies of simulation and intelligent systems to improve conventional methods of training. And the UCF faculty has deep experience in team training and performance, and this is augmented by active collaboration with the nearby Naval Training Systems Center.

This concentration of expertise in training issues could be brought to bear on needs identified in the National Plan. For example:

1. Techniques for selecting controllers, aircraft mechanics, and airway system technicians based on analyses of the skills, personality attributes, and knowledge required in the modern environment of these jobs

2. Technology for providing more effective and relevant training of controllers, mechanics, and technicians

3. Job-relevant performance assessment of controllers, mechanics, and technicians 
4. Techniques for training and evaluating team performance, especially in distributed groups of personnel

\section{Ab initio training of pilots}

Another, related domain for which the CAHFA faculty has special expertise is human factors in general aviation, including topics such as (1) the influence of cultural and cognitive factors on decision-making among general aviation pilots, and (2) helping general aviation pilots operate in an ATC environment that is increasingly crowded and automated.

\section{Georgia Institute of Technology}

Operating within the Georgia Institute of Technology's (Georgia Tech's) School of Industrial and Systems Engineering, is the Center for Human-Machine Systems Research, which has three permanent faculty members whose research focuses on the analysis, modeling, and design of human-machine systems. Much of their work is relevant to aerospace systems and some of it directly addresses flight deck issues. The backgrounds of the faculty members comprise engineering, computer science, and psychology. The Center offers both master's and doctorate programs.

Some of the research topics currently under way at the Center are as follows:

1. Graphic display aiding: intelligent displays to provide human operators the information pertinent to the task at hand in a format that sustains situational awareness

2. Modeling the elements of job tasks and the strategies humans use to handle workloads

3. Operator-intent inferencing: providing the computer a model of what the human is doing so that it can provide appropriate information and assistance; currently, the cruise-to-descent portion of the flight crew task is being modeled

4. Intelligent computer assistants: currently, a flight assistant is being worked up that would, at the discretion of the flight crew, help with some of the tasks of navigation, systems monitoring and control, and mode awareness

5. Intelligent tutors: for example, a tutor for vertical navigation (VNAV) and the mode-control panel (MCP) displays of the B757. Members of the faculty have a good working relationship with Delta and expect to integrate this tutor into Delta's glass-cockpit transition training

The research is done using state-of-the-art computational equipment and facilities that include an integrated network of Sun Sparcstations and NeXT workstations, Apple
MacIl computers and other peripherals, and software appropriate for modeling, simulation, and graphics.

The particular strength of this faculty group lies in its capabilities to design more effective ways for humans and computers to work on common tasks. Georgia Tech is one of the top engineering schools in the country, and the Center for Human-Machine Systems Research is one of the leading research groups working on supervisory control. It is desirable that flight deck automation be studied in the broader context of supervisory control issues. Georgia Tech could contribute significantly to the next generation of cockpit automated systems to improve situational awareness (e.g., awareness of the mode in which automated systems are operating) and to even out workload (e.g., in the transition from cruise to descent). Their work on intelligent tutors could also improve the effectiveness of crew training in the use of cockpit automation.

Faculty members are quite knowledgeable of flight deck automation and they have good contacts with industry on this focused issue. They recognize that they do not have broad expertise in flight operations and flight deck issues and, appropriately, do not attempt research on the broad spectrum of aviation human factors.

This faculty group collaborates to some extent with the psychology faculty at Georgia Tech (e.g., a member of the psychology faculty is a leading scientist in cognitive aspects of human factors). Expanding this kind of collaboration with behavioral scientists might be highly useful and might open up ways to more deeply integrate the human performance aspects with engineering design aspects of the issues studied.

\section{University of Illinois}

There is strong collaboration among three University of Illinois campus units: the Institute of Aviation, the Department of Psychology, and the Department of Mechanical and Industrial Engineering. About a dozen faculty members have joint appointments among the three units and the units conduct joint recruitment and tenure review for these appointments, which strengthens the interactions substantially.

In addition to the degrees offered separately by the Departments of Psychology and Mechanical and Industrial Engineering, the University of Illinois also offers an integrated graduate program (M.S. and Ph.D.) in engineering psychology and human factors. This program emphasizes the design and operation of complex systems and attracts a number of graduate students to work on aviation issues. 
NASA currently draws upon a postdoctoral fellowship program the National Research Council runs for various federal agencies to bring both junior and senior scientists into government laboratories for a year or two. This program covers the gamut of science and technology areas that concern federal agencies. It would be administratively simple and cost-effective to use this same mechanism to target aviation human factors.

Coordination-Budget limitations make coordination of the research efforts of the FAA, NASA, and the DOD crucial. This is especially crucial for the limited funding available for university grants, because the universities are especially qualified to contribute to the longer-range objectives of the National Plan and longer-range military objectives. These longer-range, strategic objectives cut across the programs and interests of all the agencies.

The university community can help federal agencies by advising them on how best to devise programs to attract the best university scientists to work on the objectives of the National Plan. In addition to inviting university scientists to serve on advisory committees, the federal agencies would benefit by having many university scientists involved in the process of evaluating the technical merit of grant proposals. This is done extensively by the NSF, NIH, and Air Force Office of Scientific Research (AFOSR), so procedures already exist to preclude problems with conflict of interest among scientists submitting and evaluating proposals.

\section{Conclusion}

The university community is contributing to the goals of the National Plan and has the potential for far greater contributions if funding is made available and if funding programs are designed with a good under-standing of the way university research is done. The capabilities of universities complement those of the industry and govern ment laboratories. Research collaborations are a particularly valuable way to combine the special capabilities of the universities and industrial and governmental laboratories. Universities also have a crucial role in preparing future generations of scientists, engineers, and managers trained in aviation human factors.

The aviation human factors community, including government, industry, and the universities, is not as powerful a research alliance as it can and should be. Particularly problematic are the fragmentation of the research in this field and the difficulty of developing powerful generic approaches that could replace large numbers of studies that do not generalize beyond a particular piece of equipment. These problems result from the complexity of the research problems, the diversity of research approaches, and the lack of systematic funding and development of aviation human factors as a field. However, recent developments in behavioral science and computer science offer rich new opportunities to study complex human behavior and system performance in real-world settings such as aviation.

DOD, NASA, and the FAA are the primary supporters of aviation human factors, as well as being among the customers for this research. These agencies must, of course, be concerned with the immediate problems of today. But, if they also look beyond these problems and invest systematically and shrewdly, they could catalyze the emergence of aviation human factors as a powerful applied discipline that will anticipate and help resolve the problems of tomorrow. 
generalize to related situations, or will the conclusion apply only to one particular design of equipment or procedure? Do the investigators have appropriate experience with the methods and equipment? Most scientists believe that research areas are so specialized that scientific merit can be evaluated only by scientists who have deep expertise in the area of the issues covered by the proposal.

Most agencies experienced in funding research have each proposal evaluated by several scientists who among them have expertise in all aspects of the proposed research. Having proposals reviewed by several experts is especially important in aviation human factors, a field in which the techniques employed are quite hetero-geneous. Also, because aviation human factors is a relatively new field, only some of its techniques are well established; others are still evolving and being refined.

Because evaluating a proposal's relevance to operational issues requires expertise in those operational issues, operational experts should be among the reviewers of proposals. Operational relevance and scientific merit are interrelated. For example, a proposal might correctly describe an operational problem, but not be relevant if the research design does not provide useful information for solving the problem. Also, if the results of the experiment cannot be extrapolated from one particular instance of a cockpit design or procedure to a more general class, those results will not be broadly useful to the operational community.

Various agencies have found technical review panels useful in providing thorough evaluations of all aspects of research proposals. A panel composed of operational experts and scientists with appropriate technical expertise, chosen to cover among them each of the major domains of aviation human factors, could help ensure that federal agencies supporting research in this domain get the most for their money.

Balancing short-, medium-, and long-range researchThe only way federal agencies can help an industry with pressing immediate problems and an industry that will face equally pressing problems 5-20 years later is to support a balanced portfolio of short-, medium-, and longrange research.

Designers of systems and procedures for cockpits and for ATC face innumerable human factors questions. If research is required for each instance, all the scientists in the world could not provide all the answers. The aviation community needs a body of human factors knowledge sufficiently generic to provide design and procedure guidelines without having to research every detail. But a problem arises here, because the operational community needs answers to many questions now; however, the generic knowledge necessary to answer those current questions could only have been generated by research conducted years before.

Stable funding-Good science requires stable funding because the time constants of research are inherently long. Opportunists may offer to "research" a problem in a year, but few of the problems facing industry will be solved this way. Furthermore, the results of a large number of 1 -year studies are not additive. The objectives of the National Plan require a much deeper understanding of complex human performance and interaction with complex systems than now exists. To achieve these objectives, federal agencies must stabilize their goals and maintain programs long enough for the scientific community to get useful results.

Getting young investigators started-The vitality of any scientific field depends on attracting first-rate young scientists. Recognizing this, federal agencies concerned with particular domains of science have set aside funds for graduate training, postdoctoral training, and start-up grants for young investigators. Many observers credit these special funding programs with enabling the scientific community to rapidly expand after World War II in areas such as biomedical research, with consequent dramatic advances in the understanding, prevention, and cure of disease.

No funds of this sort are currently earmarked for aviation human factors. This is particularly a problem for young assistant professors, who must quickly obtain a research grant or contract in order to do the research that will determine whether they get tenure. The difficulty of obtaining a first grant in aviation human factors means that a new assistant professor may be wise to stick to basic research domains, in which the probability of funding is much higher. NSF and the manufacturing industry have recently established a cooperative program of startup grants to encourage young investigators to work in manufacturing science. The FAA, NASA, and DOD might consider a similar program for aviation human factors.

These federal agencies might also achieve a large effect with a modest investment in graduate and postdoctoral research training fellowships in aviation human factors. Some of the postdoctoral fellowships might be tenable in universities, with the provision that the trainee spend summers in government or industry laboratories. In addition to providing specialized training in the particular applied problems addressed in these laboratories, this exposure might help the government and industry recruit well-trained young scientists. 
The Institute of Aviation includes a department of pilot training, a department of aircraft maintenance technology, and an aviation research laboratory. The Institute is an FAR part 141 school and has an exemption from the FAA that allows them to train students to proficiency standards without the usual set minimum number of flight hours. This exemption enables them to do research comparing traditional flight training with alternative approaches. For example, they currently have an FAA contract to compare the effectiveness of three approaches: (1) $100 \%$ flight hours, (2) substitution of conventional flight simulator time for some flight hours, and (3) substitution of PC-based training for some flight hours.

Research facilities at the Institute of Aviation include (1) three advanced all-digital flight simulators (known as ILLIMAC) used with a CompuPro microprocessor to process flight performance data; (2) a GAT-2 simulator (single-engine) used with an ABM AT computer; (3) two GAT-3 simulators (twin-jet); and (4) an IRIS 2400 aviation graphics display terminal and workstation that can be used separately or with the ILLIMACs to provide realtime visual scenes and symbolic information.

Associated campus research facilities include (1) the Visual Perception Laboratory, with an Evans \&

Sutherland 2-channel SP-X computer-generated visual display, Microvax workstation, projection systems, an IMI 600SN visual display, and two IRIS 2400 graphics workstations; and (2) the Engineering Psychology Research Laboratory, with computer facilities for evaluating voice interactive systems and an IRIS for evaluating advanced visual display concepts.

A partial list of the research activities of those faculty members with joint appointments includes the effects of factors such as drugs, aging, or cognitive impairment of pilot performance; computerized test batteries to screen cognitive functions; pilot workload and allocation of $\operatorname{cog}$ nitive resources; advanced electronic map displays for navigation; multi-media computer-based training methods and materials (e.g., to facilitate training on aircraft systems); analysis of how visual scene information is used in learning flight tasks and development of special lowfidelity simulators to enhance learning; examination of optimal display formats; effects of head-up display (HUD) optics on pilot attention; development of three dimensional perspective displays; evaluation of speech recognition and synthesis technology, developing models of pilot decision-making; and the effects of automation on crew communication.

The University of Illinois has diverse capabilities relevant to aviation human factors. I believe that the characteristic that gives Illinois its greatest strength is the close collaboration among the three departments. The psychology department, which ranks high among others in the United States, provides direct access to the latest developments in fields such as cognitive science. Several other universities have highly ranked psychology departments, but typically these do not have strong links to aviation. The Institute of Aviation provides expertise and access to aviation operations and applied research in aviation human factors. The engineering department provides a similar bridge, especially for topics involving humancomputer interaction.

A second strength of the University comes from its flight training program, which provides an opportunity for research on innovative training methods and training technology. A third strength lies is the concentration of expertise in both basic and applied cognitive science. Modern technology has changed the roles of flight crews in ways that make cognitive aspects of behavior central to the integrated performance of crew, aircraft, and ATC.

The caliber of the Illinois faculty members working on human performance issues in aviation is possibly the highest in the country and their productivity is evident. The reputations of the three departments allows them to attract top young scientists to their faculty, and-in contrast to some universities-Illinois supports applied work on aviation human factors.

Among universities doing aviation human factors research, Illinois may cover the broadest range. However, no university covers the full range of this heterogeneous field, nor should this be expected. I have the impression that the faculty members' involvement in flight deck issues comes largely through $a b$ initio training and through interaction with the FAA, NASA, and DOD and only secondarily through interaction with the air transport community. It might be useful for Illinois to expand their interaction with this community.

\section{Ohio State University}

Two faculty members of the Department of Industrial and Systems Engineering at Ohio State University (OSH) have developed a research program in cognitive systems engineering. Their research uses real-world contexts to study basic issues in human-machine cooperation such as (1) factors underlying expert performance and errors, (2) design of cooperative human-machine problem solving systems, and (3) design and use of intelligent tutoring and multimedia systems to provide educational tools. Two current projects illustrate how they are applying this research to human-computer cooperation in aviation.

First, they have developed a testbed with which they can systematically explore how experts (experienced 
dispatchers and airline pilots) make decisions about route planning in the face of weather and fuel constraints. The testbed is a planning tool that provides to the dispatcher relevant weather/route/fuel information upon request. It can also operate at several levels of automation. Research to date sheds light on how different levels of automation influence pilot performance, especially how some designs induce an increase in errors.

Second, they analyzed the effectiveness with which airline crews use the flight management system (FMS). This study had three components: (1) a survey of glass-cockpit pilots to build a corpus of automation surprises, (2) observation of glass-cockpit transition training to characterize the modes and features of the FMS found most difficult, and (3) and an experimental study of pilot interaction with cockpit automation that was concerned with the factors that contribute to breakdowns in pilot-automation coordination, including mode awareness.

In both of these studies the investigators worked closely with operational experts and gained a solid understanding of real-world air transport operations. My impression is that the work is both technically sound and highly relevant to air transport operations.

The Department of Psychology is a fairly large department whose faculty members' research interests are spread over much of the traditional spectrum of psychology. Only one of the faculty is currently working directly on problems in aviation human factors: workload measurement. However, several faculty members do research on human performance, emphasizing the fundamental aspects of attention, memory, cognition, motor skills, decision processes, and individual differences. This department recently hired a new faculty member with a background in cognitive science who will reinforce links with faculty members in engineering.

The psychology department has several well-established scientists doing respectable work in basic research areas that could be brought to bear on applied human performance issues in aviation. These faculty members could provide valuable collaboration with faculty members in other departments and institutional mechanisms exist to facilitate this (see below). Also, graduate students specializing in human performance may elect to include an applied study such as aviation in their training.

The aviation department provides flight training and aviation-related course work. Three colleges (engineering, business, and arts and sciences) offer undergraduate majors in aviation. This department has a fleet of 18 aircraft, 3 GAT-1 trainers, an ATC multi-engine simulator, and 2 ATC desktop trainers for training students.
This department sponsors the Aviation Psychology Laboratory (APL), a loosely knit group of OSU faculty members from various departments who occasionally work together to provide educational opportunities for graduate students and to do aviation research. For flight research, APL has a Beech Musketeer with an IBM XT data acquisition system. It also has a T40 jet simulator with motion platform and a GAT-1 trainer with a special purpose programmable visual display generator.

The aviation department also organizes and hosts the biennial meeting of the International Symposium on Aviation Psychology. One of the faculty members is chief editor of the International Journal of Aviation Psychology, the only technical journal devoted to this field.

OSU has recently created a Center for Cognitive Science, which sponsors seminars and encourages research and collaboration across university departments. The university has stated an interest in developing cognition as a cross-departmental strength. If this is pursued, it might also provide an impetus for aviation research. The aviation research currently under way in industrial and systems engineering is applied cognition, and many of the issues faced in the modern air transport flight deck are essentially cognitive.

Given the resources described above, OSU has the potential to be a major center in aviation human factors research.

\section{Massachusetts Institute of Technology}

Three research groups in the Department of Aeronautics and Astronautics at the Massachusetts Institute of Technology (MIT) work in aviation human factors. One group is exploring formats for electronic displays: datalink, terrain, instrument approaches, and microburst warnings. Typically, their approach is to examine the performance of experienced airline pilots in part-task simulations of an advanced cockpit on a workstation. For example, in a recent study they compared the effects of giving datalink clearances in one of three formats: oral, textual, or graphic. The study also compared entering clearances into the FMS manually versus automatically. The primary dependent variable was how well the pilots detected erroneous clearances.

The domain of this group's work is somewhat similar to that of the Georgia Tech group, although the Georgia Tech group's approach is based more on modeling and is more likely to provide results that can be generalized to different issues. The MIT group's approach is more empirical and provides a direct evaluation of specific 
design options being considered by industry. Both approaches are valuable and both groups are productive.

A second group does research on automation in the ATC system (e.g., how to keep the controller in the loop regarding the actions of automated systems). Although I did not obtain much information on this group's research, the faculty principal investigator has the reputation of being one of the major figures in this domain and seems to be quite knowledgeable of ATC issues.

The third group has done a wide range of research on the physiological and behavioral aspects of human performance in space and aviation. The aviation side includes vestibular, orientation, and motion sickness issues; flight simulation design; manual control; human error and workload in automated systems; and skill acquisition/ retention. My impression is that this group is not currently working on topics central to the National Plan but they do have the potential to contribute in some areas.

In its long-range plan, the Department of Aeronautics and Astronautics has identified human factors as one of five major areas around which to develop, but has not yet started along this line. MIT has discussed putting together a human factors/ automation laboratory in collaboration with the Department of Transportation's Volpe Transportation Systems Center in Cambridge, Massachusetts.
The Mechanical Engineering department includes one senior faculty member in human factors who has worked from time to time on aviation issues. The primary thrusts of his research group currently are telerobotics, automation, and human supervisory control. He currently has a graduate student looking at the dynamics of planning and action in multiple tasks with automated flight systems.

My impression is that the greatest strength of MIT is in effective design of automated systems and displays. MIT is, of course, one of the best engineering schools. The faculty members work closely with industry, are well acquainted with automation issues in the cockpit and ATC, and have a strong grasp of the real-world constraints of engineering design. Appropriately, they do not attempt a broad range of work in aviation human factors. Nevertheless, I feel they and their graduate students would benefit from closer interaction with behavioral scientists, who could contribute significantly to the thinking about why crew performance is affected by design options in the ways observed. Unfortunately, although Cambridge has several very strong university psychology departments, none of the faculty members in these departments work in applied human factors. 


\section{Appendix B}

\section{Literature Survey}

To get a better idea of the distribution of research in aviation human factors I conducted a literature survey in which I reviewed the papers presented at the 1991 International Symposium of Aviation Psychology and at the 1991 Annual Meeting of the Human Factors Society. In addition, I conducted a computer search of 1991 publications in this field; the search was limited to 1991 to keep the effort manageable.

The Aviation Psychology Symposium, which is held biennially, is the only regularly scheduled meeting that covers the span of this field. It is attended by scientists, human factors practitioners, and aviation operations personnel; not all the presentations are technical. Table 1 shows the distribution of papers presented, as a function of the organization of the first authors of each paper and the type of paper. Fourteen percent of the papers were collaborative efforts by authors from different types of organizations; keynote addresses and workshop summaries were excluded from the count.

Table 2 shows the distribution of papers presented at the 1991 meeting of the Human Factors Society that directly address aircrew, flight deck, or ATC issues. These 38 papers are about $12 \%$ of the total presented. A large fraction of the other papers contain data that could be applied to aerospace systems (e.g., a paper entitled "Contrast Sensitivity and English Letter Recognition"). Presentations at this annual meeting are, for the most part, aimed at a technical audience.

The computer search of aviation human factors literature proved difficult. The number of topics in this field is large and the topics are much more heterogeneous than in most fields of research. The work is published in a wide variety of journals (many of which are not devoted primarily to aviation), symposium proceedings, books, contractor reports, and government technical reports. The search was designed around conjunctions of key words to avoid being swamped by thousands of false hits, and the set of conjunctions was adjusted in several iterations to elicit as high a percentage of correct hits and as few false hits as possible. From a rough comparison with a small sample of known papers I suspect that the search probably elicited only about half of the papers published in 1991.

Another difficulty was that none of the existing computerized databases of technical literature covers aviation human factors very well. I finally settled on searching three databases: Psychological Abstracts, NASA/Recon, and NTIS. Psychological Abstracts
Table 1. Papers presented at the 1991 Aviation Psychology Symposium

\begin{tabular}{lrcr}
\hline \hline \multirow{2}{*}{$\begin{array}{c}\text { Author } \\
\text { affiliation }\end{array}$} & \multicolumn{2}{c}{ Paper type } & \\
\cline { 2 - 3 } & Research $^{\mathrm{a}}$ & $\begin{array}{c}\text { Discussion/ } \\
\text { description }\end{array}$ & Total \\
\hline Government $^{\mathrm{c}}$ & 24 & 16 & 40 \\
Industry $^{\mathrm{d}}$ & 13 & 36 & 49 \\
University & 39 & 14 & 53 \\
Foreign & 14 & 19 & 33 \\
Not available & 2 & 4 & 6 \\
Total & 92 & 89 & 181 \\
\hline \hline
\end{tabular}

ancludes all papers in which data were collected and analyzed; some of the included papers do not report scientific research but nonetheless do provide useful information.

b Includes papers with discussions of technical or operational issues, program descriptions, and research descriptions that do not include data.

cAir Force, Army, FAA, NASA, and Navy.

d About two thirds from consulting and engineering firms; remainder from airframe manufacturers, avionics companies, ALPA, and APA.

Table 2. Papers presented at the 1991 Meeting of the Human Factors Society

\begin{tabular}{lrcc}
\hline \hline \multirow{2}{*}{$\begin{array}{c}\text { Author } \\
\text { affiliation }\end{array}$} & Research & $\begin{array}{c}\text { Piscussion/ } \\
\text { description }\end{array}$ & Total \\
\cline { 2 - 4 } Government & 6 & 2 & 8 \\
Industry & 6 & 6 & 12 \\
University & 12 & 1 & 13 \\
Foreign & 5 & 0 & 5 \\
Total & 29 & 9 & 38 \\
\hline \hline
\end{tabular}

primarily covers journals in the behavioral sciences. NASA/Recon provides on-line access to the Aerospace Database, which is co-produced by AIAA and NASA. Its coverage includes journal articles, conferences, books, theses, and unpublished report literature; however, coverage of publications that are not primarily devoted to aerospace is quite limited. NTIS primarily covers government technical reports. There was considerable overlap in the technical reports elicited from NASA/Recon and NTIS. Eliminating the duplications manually would have been very time consuming, so I used NTIS only to extend the list of universities doing research in aviation human factors. 
The search produced 34 articles published in 14 journals (table 3), 30 contractor and government technical reports, 30 symposium proceedings papers, 4 dissertation abstracts, 5 articles in books, and 3 articles in house publications (Reports of Aeromedical Laboratory [Japan] and Kansas Aviation Review). The search strategy may have had hidden biases in sampling different types of literature, and some studies were probably published in more than one form; thus, these numbers are unlikely to be precisely representative. Nevertheless, they suggest that a large part of the work in aviation human factors does not appear in peer-reviewed journals, which raises questions about the breadth of the distribution of information, the availability of details about experimental design and analysis of data, and the rigor of quality control in some of the research. A careful reading of research reports supports this concern.

Of the 106 articles identified in the search, 33 were from government agencies, 25 from industry, 27 from universities, and 21 from foreign organizations. Combining information from the computer search, the Aviation Psychology Symposium, and the Meeting of the Human Factors Society, I identified 52 U.S. universities (table 4) whose faculty members contributed papers in 1991 . I suspect my search missed at least a few universities.

Of course, those universities with more faculty members working on aviation human factors published more in this area than did other universities, but it is noteworthy that the work in this field is distributed so widely. It appears that over half of the literature from universities comes from schools that have only one or two faculty members working in this area. Also, some university scientists

Table 3. Journals identified in computer literature search

\begin{tabular}{l}
\hline \hline Aviation, Space \& Environmental Medicine \\
Behavioral Research Methods, Instruments, \& \\
Computers \\
Canadian Aeronautical \& Space Journal \\
Ergonomics \\
Flight International \\
Forensic Reports \\
Human Factors \\
ICAO Journal \\
IEEE Aeronautical \& Electronic Systems Magazine \\
International Journal of Aviation Psychology \\
International Journal of the Addictions \\
Journal of Applied Psychology \\
Kosmicheskaya Biologiya i Aviakosmicheskaya \\
Meditsina \\
Military Psychology
\end{tabular}

Table 4. University sources of papers related to aviation human factors

\begin{tabular}{ll}
\hline Univ. of Alabama (Tuscaloosa) & Ohio State Univ. \\
Arizona State Univ. & Oklahoma St. Univ. of \\
Univ. of Arizona & Agriculture \& Applied \\
Univ. of California (Davis) & Sciences \\
Catholic Univ. & Old Dominion Univ. \\
Univ. of Cincinnati & Oregon State Univ. \\
Univ. of Dayton & Penn. State Univ. \\
Univ. of Denver & Princeton Univ. \\
Embry-Riddle Aero. Univ. & Purdue Univ. \\
George Mason Univ. & Samford Univ. \\
Georgia Inst. of Technology & San Jose State Univ. \\
Hampton Institute & South Dakota Univ. \\
Univ. of Illinois & Stanford Univ. \\
Univ. of Kansas & Univ. of So. Calif. \\
Kent State Univ. & Texas Tech. Univ. \\
Massachusetts Inst. of Tech. & Univ. of Texas, Austin \\
Univ. of Michigan & Vanderbilt Univ. \\
Univ. of Miami & Virginia Polytechnic \\
Univ. of Minnesota & Inst. \& State Univ. \\
Montclair State College & Villinova Univ. \\
Univ. of New Haven & Univ. of Virginia \\
Univ. of New Orleans & Univ. of Washington \\
New Mexico State Univ. & Wichita State Univ. \\
Univ. of New Mexico & William \& Mary Col. \\
State Univ. of NY, Binghamton & Wisconsin Univ. \\
State Univ. of NY, Buffalo & Wittenberg Univ. \\
Univ. of North Dakota & Wright State Univ. \\
Ohio Univ. & \\
\hline \hline & \\
\hline &
\end{tabular}

work on a range of human factors issues, including but not limited to aviation applications. Furthermore, many important contributions to aviation human factors come from research that is not specific to aviation. For example, the Human Factors Engineering Center at Virginia Polytechnic does considerable research on the effects of display characteristics on human visual performance. This research, and related work from other organizations, is used by avionics manufacturers in the design of cockpit displays.

In the U.S., industry, government, and universities contribute about equally to the volume of literature on aviation human factors; however, universities contribute a disproportionately large part of the literature containing research data.

It is difficult to estimate how many scientists work in aviation human factors. The Aerospace Systems Technical Group of the Human Factors Society has 552 members, some of whom are researchers and some practitioners. (Affiliations listed by the members: 
industry, 247; student, 130; government, 104; university, 59; government-owned contractor-operated laboratories; 5; nonprofit institute, 1). The Association of Aviation Psychologists has a comparable membership, which overlaps that of the Aerospace Systems Technical Group. Many scientists active in aviation human factors research do not belong to either group. A recent study by the National Research Council (Human Factors Specialists' Education and Utilization) found that $21.6 \%$ of human factors practitioners work primarily on aerospace problems. Unfortunately, comparable figures are not available for scientists doing research on aerospace problems.

\section{References}

1. Albers, J. A.: Aviation Safety and Automation Technology for Subsonic Transports. NASA TM-103831, 1991.
2. National Plan to Enhance Aviation Safety through Human Factors Improvements. Recommendations of the Air Transport Association Task Force. Air Transport Association, Washington, DC, 1989.

3. Safe Skies for Tomorrow: Aviation Safety in Competitive Environment. Office of Technology Assessment, U.S. Congress, Washington, DC, 1990.

4. Wiener, E. L.; and Nagel, D. C., eds.: Human Factors in Aviation. Academic Press, San Diego, Calif., 1988.

5. The National Plan for Aviation Human Factors. Federal Aviation Administration, Washington, DC, 1990. 
Public reporting burden for this collection of information is estimated to average 1 hour per response, including the time for reviewing instructions, eearching existing data sources, gathering and maintaining the data needed, and completing and reviewing the collection of information. Send commente regarding this burden estimate or any other aspect of this collection of information, including suggestions for reducing this burden, to Washington Headquarters Services, Directorate for information Operations and Reports, 1215 Jefferson Davis Hlghway, Sulte 1204, Artington, VA 22202-4302, and to the Office of Management and Budget, Paperwork Reductlon Project (0704-0188), Washlngton, DC 20503.

1. AGENCY USE ONLY (Leave blank)

2. REPORT DATE

March 1994
3. REPORT TYPE AND DATES COVERED

Technical Memorandum

4. TITLE AND SUBTITLE

Aviation Human Factors Research in U.S. Universities: Potential Contributions to National Needs

6. AUTHOR(S)

$505-64-13$

R. Key Dismukes

7. PERFORMING ORGANIZATION NAME(S) AND ADDRESS(ES)

8. PERFoRMING ORGANIZATION REPORT NUMBER

Ames Research Center

Moffett Field, CA 94035-1000

A-94060

9. SPONSORING/MONITORING AGENCY NAME(S) AND ADDRESS(ES)

National Aeronautics and Space Administration

Washington, DC 20546-0001

10. SPONSORING/MONITORING AGENCY REPORT NUMBER

NASA TM-108814

11. SUPPLEMENTARY NOTES

Point of Contact: R. Key Dismukes, Ames Research Center, MS 262-1, Moffett Field, CA94035-1000 (415) 604-6150

12a. DISTRIBUTION/AVAILABILITY STATEMENT

12b. DISTRIBUTION CODE

Unclassified-Unlimited

Subject Category - 03

\section{ABSTRACT (Maximum 200 words)}

Universities can and should make vital contributions to national needs in aviation human factors. However, to guide and utilize university research effectively we must understand what types of expertise and facilities universities can bring to bear on aviation problems. We should be aware of where relevant research is already underway and where untapped potential exists. How does the character of research in universities differ from and complement research in government and industry laboratories? What conditions would encourage universities to focus on national priorities and would promote high quality, relevant research? This paper attempts to address these issues. It is based on a survey conducted by the author, which included site visits to several universities, telephone interviews with faculty members at other universities, and a search of the aviation human factors research literature.

\section{SUBJECT TERMS}

Aviation human factors, National needs, University research

15. NUMBER OF PAGES

26

16. PRICE CODE

$\mathrm{A03}$

\begin{tabular}{l|l}
\hline 17. SECURITY CLASSIFICATION & 18. SECURITY CLASSIFICATION \\
OF REPORT & OF THIS PAGE \\
Unclassified & Unclassified \\
\hline
\end{tabular}

19. SECURITY CLASSIFICATION

20. LIMITATION OF ABSTRACT 



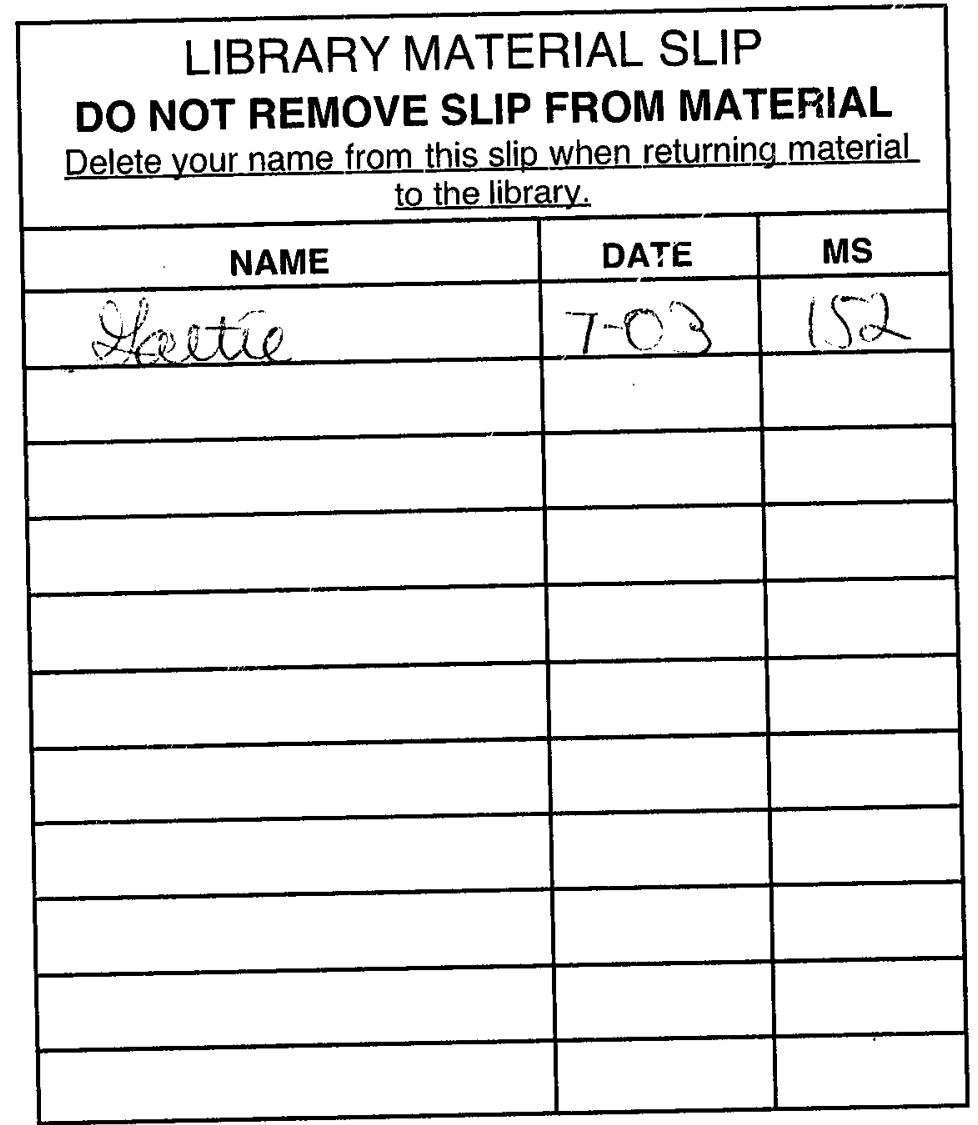

NASA Langley Form 474 (Rev. Oct. 1999) 